\title{
OURO PRETO DOS POETAS MODERNISTAS
}

\author{
Marcia Arruda Franco \\ marciarrudafranco@gmail.com
}

Para OMS

Desde o tempo de Cláudio Manuel da Costa até o momento presente, os poetas brasileiros vêm dedicando poemas à cidade de Ouro Preto, por uma série de razões ${ }^{1}$. Aqui, porém, nos restringiremos à relação que existe entre alguns poetas modernistas e a preservação do patrimônio arquitetônico colonial.

O interesse do grupo modernista ${ }^{2}$ pelas cidades históricas de Minas começa dois anos após a Semana de Arte Moderna, em 1924, quando, acompanhando Blaise Cendrars, Oswald de Andrade, Tarsila do Amaral, Mário de Andrade, Paulo Prado, D. Olívia Guedes Penteado e outros visitaram as cidades históricas de Minas Gerais, na famosa "viagem de redescoberta do Brasil". Imediatamente houve uma repercussão na concepção poética de Oswald de Andrade: estava fundada a poesia PauBrasil, "poesia de exportação", "oposta ao espírito eà forma de importação", e que "aproveitava os elementos desprezados da cultura nacional"

1. Veja-se, na bibliografia, Antologia Poética de Ouro Preto (CARDOSO FILHO, 1995).

2. Refere-se aqui a um interesse coletivo do grupo modernista. É sabido que Mário de Andrade visitou as cidades históricas em 1919 (SOUZA, 1993, p. 45), quando veio a conhecer Alphonsus de Guimaraens em Mariana. Data de então o seu interesse pela obra e pela figura do Aleijadinho. 
(ANDRADE, 1990, p. 22), dos quais fazia parte o conjunto arquitetônico barroco. O modernismo assumia a sua contradição essencial: na busca do novo, encontrava, através do velho, uma identidade genuinamente brasileira, encontrava uma tradição brasileira - no presente, o passado. À medida que o conjunto arquitetônico barroco era valorizado, a relação dos artistas brasileiros com o modelo europeu ia sendo revista.

$\mathrm{Na}$ "Crônica de Malazarte VIII", de Mário de Andrade, sobre a viagem de 1924 a Minas, Tarsila do Amaral quer voltar a Paris, não para participar de movimentos vanguardistas, mas para "adquirir um saber que proporcionasse a restauração” (SANTIAGO, 1989, p. 106) do patrimônio colonial brasileiro, em estado lastimável:

Volto a Paris, mas para me aperfeiçoar ainda mais nos processos de restauração de pinturas. Depois volto a Minas. É preciso conservar tantos tesouros. Eu estou pronta. E sem nenhuma paga. Que remuneração melhor para mim que restituir à pequena e maravilhosa Rosário de São João del Rei o esplendor passado do seu teto? (Apud SANTIAGO, 1989, p. 106)

Em entrevista ao Diário de Minas, em 27 de abril de 1924, antes de a embaixada modernista seguir para Ouro Preto, Oswald chama a atenção para a necessidade de preservação da arquitetura colonial, pois a "civilização do ouro, representada pela velha Minas está num mesmo patamar de "qualquer das civilizações correspondentes da Europa":

A arquitetura de São João del Rei, Tiradentes e Sabará e de outras que vamos percorrer está aí como uma censura viva aos inconscientes que pretendem transplantar para o nosso clima o horror dos bangalôs e das casas de pastelaria. As cores vivas e o aspecto sólido e calmo das casas mineiras é a melhor lição que pode ser dada aos nossos construtores. Como é um crime substituir, nos altares, as velhas imagens maravilhosas feitas à mão pelos nossos melhores santeiros por uma súcia de santos almofadinhas e sem caráter definido, saídos da industrialização italiana e alemã, é outro crime desprezar o cor-de-rosa das fachadas, o abrigo dos beirais e azul das janelas - nascidos da paisagem brasileira e da tradição, e tão naturalmente de acordo com elas - pelas cores cinzentas da Europa (ANDRADE, 1990, p. 16).

E acrescenta: "O que é preciso é defender as cidades que têm um caráter marcado e antigo. Nessas não há necessidade de transformações. Que se adapte o velho e lindo estilo colonial às necessidades de conforto e aumento" (ANDRADE, 1990, p. 17).

É este mesmo entusiasmo com a preservação da arquitetura colonial que ainda se mantém em outra entrevista, feita em Recife, no ano seguinte, 1925, a bordo do Avon, quando Oswald se dirigia ao Velho Mundo, provavelmente para a publicação da primeira edição do livro 
de poesia Pau-Brasil pela editora dirigida por Blaise Cendrars, Au Sans Pareil, como nos informa AMARAL (1997, p. 15). O poeta aproveita para esclarecer o elogio do velho e do novo no modernismo brasileiro:

Linda cidade, o Recife. [...] Sinto-me brasileiro aqui. Aos pernambucanos compete trabalharem para que não desapareça, e, antes, fulgure mais intensamente, o espírito de brasilidade. Veja as cores dessas casas antigas: excelentes, repare na pintura dessas casas modernas: horríveis. Horríveis para nós, para o nosso ambiente. A arquitetura deve refletir a paisagem. A daqui apresenta tonalidades diversas, sedutoras, maravilhosas. Por que não aproveitá-la no cadinho da arte? Por que abandoná-la pela importação estrangeira? E não se pense que há incoerência nas minhas expressões, porque sou modernista. Sou-o, sobretudo, por ser brasileiro. Quero, por isso, a formação de uma arte nacional, que se há de extrair, sem dúvida, da obra dos antepassados (ANDRADE, 1990, p. 36).

No "Roteiro de Minas", parte do livro de poemas Pau-Brasil, denuncia-se, a partir de uma linguagem substantiva, a decadência das cidades mineiras, por exemplo, o poema intitulado "são josé del rei":

Bananeiras

O Sol

O cansaço da ilusão

Igrejas

O ouro na serra de pedra

A decadência (ANDRADE, 1978, p. 134)

O poema é composto de sintagmas nominais, referidos ora à natureza, ora ao contexto cultural mineiro. A ausência total de verbos contribui para o "imobilismo da decadência" (LIMA, 1972, p. 77) em "são josé del rei". Na primeira estrofe do poema "ouro preto", o signo do abandono reaparece:

Vamos visitar São Francisco de Assis

Igreja feita pela gente de Minas

O sacristão que é vizinho da Maria Cana-Verde

Abre e mostra o abandono

Os púlpitos do Aleijadinho

O teto do Ataíde (ANDRADE, 1978, p. 140)

A preocupação com a preservação da arquitetura e das imagens coloniais levará o grupo a planejar uma forma de preservar o patrimônio mineiro, segundo depoimento de D. Carolina Penteado da Silva e Godofredo da Silva Telles, que também participou da embaixada modernista a Minas, a Aracy Amaral: 
[...] depois da viagem de Minas, todo o grupo modernista elaborou um plano para a formação de uma Sociedade dos Amigos das Velhas Igrejas de Minas Gerais. O objetivo seria a preservação das igrejas preciosas tão abandonadas, como tinham tido oportunidade de observar. "Padres vendiam imagens por dificuldades financeiras", declarou-nos Godofredo da Silva Telles, "algo precisava ser feito". A primeira reunião realizou-se em casa de d. Olívia Guedes Penteado, na volta da viagem (AMARAL, 1997, p. 85, n. 1).

A revolução de 24 põe fim a este projeto modernista, pois os interessados se dispersaram em suas fazendas no interior paulista (AMARAL, 1997, p. 130). O ideal de Tarsila e Oswald - o restabelecimento da identidade brasileira, a partir da valorização do passado artístico barroco -, contudo, reaparece na década seguinte e toma uma dimensão oficial. Nove anos adiante, em 12 de julho de 1933, pelo Decreto n. 22.928, a cidade de Ouro Preto é declarada Monumento Nacional. A ligação entre o movimento modernista e a preservação de Ouro Preto, no entanto, institucionaliza-se, à medida que, ao longo da década de 30, os poetas modernistas aproximam-se do Ministério da Educação e Saúde Pública de Gustavo Capanema para a criação da SPHAN, Secretaria do Patrimônio Histórico e Artístico Nacional, efetuada entre 1936 e 1937, sendo o jornalista Rodrigo Mello Franco de Andrade o seu diretor até 1967. Para Rodrigo, à SPHAN, como desdobramento do Movimento Modernista, caberia a tarefa de elaborar o "Documento de Identidade da Nação Brasileira” (FURTADO, 1987, p. 35).

Carlos Drummond de Andrade, por sugestão do mesmo Rodrigo, desde 1928, está empregado no serviço público mineiro, na Secretaria de Educação. Em 1930, de "auxiliar de gabinete de Cristiano Machado, Secretário do Interior, ao irromper da revolução de Outubro, [...] passa a Oficial de Gabinete, quando Gustavo Capanema substitui Cristiano Machado" (HOUAISS, 1972, p. 162). Em 1933, acompanha Gustavo Capanema, quando este foi Interventor em Minas. Amigos desde 1916 - conheceram-se como alunos internos do Colégio Arnaldo, da Congregação do Verbo Divino, em Belo Horizonte -, o poeta transferese, em 1934, para o Rio de Janeiro, como Chefe do Gabinete de Gustavo Capanema, agora ministro da Educação e Saúde Pública. Em 1945, Rodrigo Mello Franco o chama para trabalhar na SPHAN, logo transformada em DPHAN, Diretoria do Patrimônio Histórico e Artístico Nacional, onde mais tarde se tornará chefe da seção de História, na Divisão de Estudos e Tombamentos. Em 1961, Drummond se aposenta como chefe da DPHAN, após 35 anos de serviço público (HOUAISS, 1972, p. 160-166).

O poeta mineiro dedicou uma parte de Claro Enigma, "Selo de Minas”, a Ouro Preto. A maior parte dos poemas, contudo, são digressões 
lírico-filosóficas sobre o contexto mineiro e não tematizam a questão da preservação da arquitetura colonial, com a exceção de "Morte das casas de Ouro Preto", que aponta para a ameaça da chuva sobre os casebres de taipa: "Sobre o tempo, sobre a taipa, / a chuva escorre. As paredes / que viram morrer os homens, / que viram fugir o ouro, / que viram finar-se o reino, / que viram, reviram, viram, / já não vêem. Também morrem” (ANDRADE, 1983, p. 276). O jogo de sentidos proposto entre os verbos ver, rever, revirar e virar resume o estado precário e o valor histórico das casas de Ouro Preto.

Mário de Andrade, em 24 de março de 1936, tinha concluído o anteprojeto do SPAN, Serviço do Patrimônio Artístico Nacional, elaborado a pedido de Gustavo Capanema, em virtude da experiência do polígrafo paulista como diretor do Departamento Municipal de Cultura de São Paulo. Entre abril de 1937 e 1938, Mário de Andrade é Assistente Técnico da 6a Região Administrativa da SPHAN. Em 1938, depois da desintegração do Departamento Municipal de Cultura de São Paulo, vai para o Rio de Janeiro, onde continua a colaborar com a SPHAN. Em abril de 1941, novamente em São Paulo, Mário já está oficialmente designado para servir no $4^{\circ}$ Distrito da SPHAN. É incumbido por Rodrigo de realizar a leitura e o fichamento sistemático de Testamentos e Inventários paulistas. Mais gratificante para o escritor foi escrever a monografia sobre o Padre Jesuíno do Monte Carmelo, tarefa que o absorveu até o final da vida. A ligação de Mário com a SPHAN permanece mesmo depois de morto, ao doar para o serviço o Sítio e a Capela de Santo Antônio, exigindo o uso conveniente do monumento tombado como repouso de artistas brasileiros. Nos oito anos em que foi funcionário da SPHAN, Mário de Andrade trabalhou para a identificação do patrimônio colonial paulista, descobrindo, em viagens de fim de semana pelo interior do estado, raridades arquitetônicas, como a capela paulista do século XVII, nos arredores da cidade de São Roque, hoje no km 8 da Estrada Mário de Andrade. Mais tarde, quando, em 1961, a DPHAN, Diretoria do Patrimônio Histórico e Artístico Nacional, adotar uma concepção arqueológica de patrimônio, tanto o anteprojeto de Mário de Andrade para o SPAN como a sua experiência no Departamento de Cultura serão referências básicas³.

Esta ligação entre o Estado e a Cultura (LIMA, 1987, p. 18) ou entre o artista-intelectual e o funcionalismo público é geralmente, de forma um tanto apressada, vista de maneira negativa: enfatiza-se a relação

3. Neste parágrafo, usamos informação obtida através da leitura do texto introdutório de Lélia Coelho Frota a ANDRADE, 1981. 
de amizade como requisito sine qua non para a obtenção de um cargo público no Brasil; salienta-se a frustração do intelectual-funcionário público ao ver o seu projeto encalhado nas gavetas da burocracia, ou mutilado por uma visão elitista da cultura e do patrimônio.

No primeiro caso estaria Drummond. O segundo é o caso de Mário de Andrade, que viu a "generosidade etnográfica" do seu anteprojeto, a incluir as culturas popular e índia, ser preterida por uma visão que privilegiava a preservação da arquitetura barroca. Na carta de trabalho a Rodrigo Mello Franco de Andrade, de 29 de junho de 1936, pondera: "Li seu projeto de lei que achei, pelos meus conhecimentos apenas, ótimo. Aliás, preliminarmente é preciso que eu lhe diga com toda a lealdade que, dado o anteprojeto ao Capanema, eu bem sabia que tudo não passava de anteprojeto" (ANDRADE, 1981, p. 6o). Ao comentar as críticas de Heloísa Alberto Torres ao seu Museu Etnográfico, Mário esclarece a sua visão da etnografia: "D. Heloísa, ao entender etnografia pelas suas especializações só pensa em etnografia ameríndia, ao passo que eu, pelas minhas especializações, entendo principalmente etnografia popular" (ANDRADE, 1981, p. 6o). Na sequência da carta, ao discorrer sobre os modos de exposição e de divulgação do acervo popular, num tom emocionado, evidencia a amplitude do seu projeto de preservação cultural: "imagine um museu etnográfico fornecendo modelos de decoração, processos de fazer rendas, chapéus de palha, etc., músicas e danças, etc., generalizando, entradicionalizando, protegendo contra o progresso mortífero etc. Não é só expor (a coisa me está doendo...) mas agir" (ANDRADE, 1981, p. 61). Na carta de 13 de abril de 1937, já na função de Assistente Técnico, o escritor pergunta, não sem certa ironia: "Quais os serviços a iniciar imediatamente? São todos, ou só a arquitetura colonial?" (ANDRADE, 1981, p. 66).

Aqui o lugar comum é criticar a postura elitista da SPHAN, que, "entronizando o barroco", "buscou salvar do abandono os exemplares arquitetônicos considerados esteticamente significativos para uma história das formas e estilos da classe dirigente brasileira" (MICELI, 1987, p. 45). As relações entre a Cultura e o Estado, porém, devem ser vistas fora do círculo estreito da má consciência burguesa. A cultura só será um bem regular, contínuo e, quiçá, coletivo, se for subsidiada pelo Estado (LIMA, 1987, p. 27). Na possível "cooptação" do intelectual modernista pelo Estado Novo, existe um saldo efetivo, certamente aquém do ideal de participação social dos intelectuais envolvidos. Os modernistas, como funcionários-públicos e como artistas, desempenharam um papel chave na preservação do patrimônio arquitetônico do Brasil colônia. Em poemas, crônicas, entrevistas, cartas particulares e em estudos 
encomendados pela SPHAN, há uma preocupação central: denunciar o estado precário e decadente do patrimônio, não só chamando a atenção para a urgência da restauração, mas também criando "conceitos e critérios de preservação" (MATTA, 1987), como o da harmonia sem imitação, fugindo ao fingimento colonial, e o das ações corretivas, isto é, da retirada de frontões e platibandas características da tímida evolução de Ouro Preto posterior ao século XVIII. No primeiro caso está a construção do Grande Hotel e, no segundo, a restauração do edifício do Cinema Vila-Rica.

Manuel Bandeira, também membro do conselho consultivo do órgão, em 1938, recebeu do diretor da SPHAN a encomenda do Guia de Ouro Preto, que não deve ser lido apenas como guia turístico ${ }^{4}$, pois representa um esforço de difusão dos critérios modernistas de preservação adotados pela SPHAN, que encarava a cidade de Ouro Preto como um bem patrimonial imóvel, isto é, como uma cidade-monumento. No Guia, a construção moderna do Grande Hotel é justificada da seguinte maneira:

Coube à Diretoria do Patrimônio Histórico Artístico e Nacional resolver o
difícil problema de dotar a cidade com uma casa, onde viajantes e turistas
encontrassem agasalho e conforto, e que não atentasse contra a fisionomia
tradicional de Ouro Preto. A solução, realmente feliz, foi do arquiteto Oscar
Niemeyer, que levou em conta umas tantas características comuns à técnica
do concreto armado e à do pau-a-pique. Seja dito que o arquiteto não quis,
absolutamente, imitar a aparência das edificações antigas, sabendo o que há
de artificioso e de falso nessa imitação, e temendo, muito acertadamente, que
viesse a passar como antigo o que é afinal, do nosso tempo. Procurou antes
fazer com que o hotel, necessariamente moderno, se destacasse o menos
possível na paisagem colonial. Fez obra de boa arquitetura atual, e esta, como
assinala um entendido, vai sempre bem com a boa arquitetura de um período
anterior; o que não combina é a falta de arquitetura (BANDEIRA, [s. d.], p. 77).

O “entendido" é Lúcio Costa, também técnico especialista da SPHAN, que, em carta a Rodrigo Mello Franco, defende o projeto de Niemeyer, fundado na mesma visão modernista:

Da mesma forma que um bom ventilador e o telefone sobre uma mesa seiscentista ou do século XVIII não podem constituir motivo de constrangimento para os que gostam verdadeiramente de coisas antigas [...] assim também a construção de um hotel moderno, de boa arquitetura, em nada prejudicará Ouro Preto (COSTA apud MATTA, 1987, p. 110).

4. Para uma análise diversa do Guia de Ouro Preto (BANDEIRA, [s.d.]), ver SCRAMIM, 2009. 
O arquiteto, por sua vez, termina o parágrafo citando, como se verá abaixo, o Guia de Ouro Preto: "E as duas grandes sombras, cuja presença o Manuel sentiu tão bem, avultarão - lendárias, quase irreais" (COSTA apud MATTA, 1987, p.110). A crítica ao aspecto bastardo de algumas construções reaparece em outro texto de Bandeira, dedicado a Rodrigo Mello Franco de Andrade (SILVA, 1989, p. 440, n. 18), "Crônicas da Província do Brasil": "[...] O caso da Câmara de Sabará é típico porque põe um ao lado do outro o padrão inspirador e o pastiche desvirtuado, num contraste verdadeiramente grotesco" (BANDEIRA, 1997, p. 57). Esses critérios de preservação fundamentavam-se, de um lado, na valorização do barroco mineiro e da Inconfidência Mineira como momentos históricos emblemáticos da identidade brasileira e, de outro, numa visão estática da cidade-monumento, "como cidade que não mudou", na expressão do Guia de Ouro Preto (BANDEIRA, [ s. d.] ).

A revigorização econômica da região, o chamado ciclo do alumínio, exigiu, porém, a construção de casas novas em Ouro Preto, tanto no centro histórico como na periferia. Os critérios modernistas de preservação da SPHAN acabaram, na prática, em virtude do número cada vez maior de casas construídas, por gerar uma arquitetura híbrida, fingidamente colonial. O crescimento urbano levou a uma redefinição dos critérios oficiais de preservação. A noção de "cidade-monumento" é particularizada na de "sítio-tombado", admitindo-se o tombamento de apenas certas áreas da cidade (MATTA, 1987). A função do órgão também foi repensada, excluindo-se a ajuda financeira: hoje, a ação do IPHAN, Instituto do Patrimônio Histórico e Artístico Nacional, é restrita à assessoria técnica e à fiscalização de obras para a manutenção da arquitetura colonial.

Bandeira, por sua vez, percebe a contradição entre a Ouro Preto cidade concreta, que a DPHAN tenta preservar, e a "tombada" nas telas de Guignard, numa crônica intitulada "Ouro Preto remoçada":

[Em Minas] quem mais ganhou com a presença de Guignard foi Ouro Preto, que hoje está definitivamente tombada na obra do pintor (o tombamento oficial não será talvez suficiente para poupar a velha cidade-monumento-nacional, pois nem a zelosa DPHAN nem o clamor de alguns poucos interessados nas relíquias do nosso passado histórico e artístico têm conseguido impedir que continue a abalar a estrutura do casario a circulação do tráfego pesado). Nesta exposição são numerosas as telas que fixam o encanto da paisagem ouropretana. [...] A Ouro Preto de Guignard não é triste, Guignard remoça Ouro Preto, sem no entanto a descaracterizar (BANDEIRA, 1986, p. 57).

Nos seus poemas sobre Ouro Preto, contudo, Bandeira não fixou uma cidade remoçada, e sim chamou a atenção quer para aquilo que a 
caracterizou historicamente, quer para a precariedade contemporânea do conjunto arquitetônico. Manuel Bandeira dedica dois poemas a Ouro Preto, o soneto que abre a Lira dos Cinquent'anos, e outro que está em Opus 10, de 1952. O soneto Ouro Preto escrito em 1928, e publicado na Ilustração brasileira, serve de epígrafe ao Guia de Ouro Preto, cuja primeira edição é de 1938. Exortando Mário de Andrade a publicar o Macunaíma, ressente-se de um modernismo que negue o passado colonial e a cultura europeia com uma desgastante brasilidade: "Eu ando tão aporrinhado que fiz um soneto sobre Ouro Preto, sim senhor! Soneto alexandrino, com enjambements e chave de ouro do Tripuí" (MORAES, 200o, p. 384). O soneto pode ser interpretado à luz do Guia de Ouro Preto, escrito dez anos mais tarde 5 . O primeiro quarteto,

Ouro branco! Ouro preto! Ouro podre! De cada

Ribeirão trepidante e de cada recosto

De montanha o metal rolou na cascalhada

Para o fausto d'El-Rei, para a glória do imposto

(BANDEIRA, 1993, p. 167),

parece explicado nos parágrafos:

Os paulistas não faziam caso nenhum do ouro da serra de Itatiaia. Era o ouro branco, de pouco rendimento, e assim chamado por sua cor pálida, quase argentina. O ouro bom, o ouro cobiçado, era o ouro preto, o ouro fino, chegava a quase vinte e três quilates [...].

Quando em 1704, Pascoal Guimarães, mascate português enriquecido no Rio das Velhas, meteu-se de posse das catas abandonadas pelos Camargos, iniciou a mineração pelo processo de desbancar o terreno por levadas de água. Sucedeu que no flanco da serra por onde hoje passa o caminho das Lajes, deu com um veio riquíssimo. Ali o metal era como terra... Ouro podre! Esse ouro excelente e tão fácil de colher foi que verdadeiramente fundou a [...] Vila Rica de Albuquerque, do nome do [...] capitão-general da nova capitania de São Paulo e Minas do Ouro. Logo depois esse nome era encurtado para Vila Rica, por haver D. João V desaprovado a denominação dada à sua revelia (BANDEIRA, [s.d.], p. 22).

O segundo quarteto enfoca o momento presente à escrita do soneto, em que o poeta só vê "Cinza e desgosto!":

5. O Guia de Ouro Preto (BANDEIRA, [s.d.]), editado várias vezes, teve segunda edição francesa. Consultamos a quarta edição sem data, que busca reproduzir o aspecto gráfico das anteriores e adiciona textos de Carlos Drummond de Andrade escritos com a documentação do IPHAN. Ver os Agradecimentos de Bandeira à quarta edição. 
Que resta do esplendor de outrora? Quase nada:

Pedras... templos que são fantasmas ao sol-posto.

Esta agência postal era a Casa de Entrada...

Este escombro foi um solar... Cinza e desgosto! (BANDEIRA, 1993, p. 167)

Entre 1928, ano da primeira viagem de Bandeira a Minas e da primeira publicação do soneto na Ilustração brasileira, 1937, como consultor da SPHAN, 1938, com o Guia de Ouro Preto, e 1940, ano da publicação de Lira dos Cinquent'anos, o poeta, deambulando por Ouro Preto, denuncia o estado precário do patrimônio: "templos que são fantasmas". "O bandeirante decaiu - é funcionário". Os que descobrem os tesouros de Ouro Preto são os poetas-funcionários da SPHAN? A casa dos contos virou os Correios e Telégrafos. No último terceto, a referência ao Aleijadinho: "E avulta apenas, quando a noite de mansinho / Vem, na pedra-sabão lavrada como renda, / - Sombra descomunal, a mão do Aleijadinho!". O famoso estudo de Mário de Andrade sobre o Aleijadinho também foi publicado em 1928 na Ilustração brasileira. Em carta de 23 de agosto desse ano anuncia a publicação do soneto "Ouro Preto" e o ensaio de Mário de Andrade para o número seguinte do mesmo periódico: "Bom, vou sair. Agora o Álvaro Moreyra reúne às quintas para jantar. Sou do cordão como colaborador das revistas (No n.o de junho da Ilustração saiu o meu soneto parnasiano sobre Ouro Preto; no próximo n.o de julho sai o artigo sobre o Aleijadinho)" (MORAES, 2000, p. 399) ${ }^{6}$. No Guia de Ouro Preto, a imagem da sombra da arte e da arquitetura colonial duplica-se na sombra do mártir da Inconfidência mineira, para o deambulador da cidade histórica. "As duas grandes sombras de Vila Rica” é parte do título do capítulo cuja primeira frase é: "As duas grandes sombras de Ouro Preto, aquelas em que pensamos invencivelmente a cada volta de rua, são o Tiradentes e o Aleijadinho"(BANDEIRA, [s.d.], p. 59). O soneto é uma aproximação histórica dos símbolos da cidade mineira, através do contraste entre o passado que avulta pela arte do Aleijadinho e a decadência atual dos escombros da arquitetura barroca.

O segundo poema que Manuel Bandeira dedica a Ouro Preto aparece num livro que veio a lume 24 anos depois da composição do soneto. "Minha gente, salvemos Ouro Preto", contemporâneo do poema de Drummond acima citado, de 1952, versa sobre o mesmo tema: é um pedido de ajuda para a cidade "avozinha" que "as chuvas de verão ameaçam derruir". Ao invés das edificações e chafarizes com valor histórico, que, na década de 30, como nos informa o Guia de Ouro Preto, teriam sido restaurados

\footnotetext{
6. Trata-se dos números 94 e 95 da Ilustração brasileira.
} 
pela SPHAN, Bandeira denuncia o estado precário dos casebres de pau a pique fortemente atingidos pelas chuvas:

As chuvas de verão ameaçaram derruir Ouro Preto.

Ouro Preto, a avozinha, vacila.

Meus amigos, meus inimigos,

Salvemos Ouro Preto (BANDEIRA, 1993, p. 219)

Bandeira se dirige não só aos seus amigos que criaram a SPHAN, mas também aos inimigos. Vale a pena citar o depoimento de Antonio Candido sobre o clima de amizade representativo da SPHAN: "Para mim o Patrimônio Histórico foi sobretudo uma questão de amizade [...]. Sempre que ia ao Rio eu dava um pulo até ao seu [de Rodrigo] escritório no Ministério da Educação, onde encontrava gente como Manuel Bandeira, Carlos Drummond de Andrade [...]" (CANDIDO, 1987, p. 40). Quem seriam os inimigos referidos pelo poeta? Manuel Bandeira interpela os homens e mulheres de bem, as elites paulista e carioca, pedindo-lhes doações para a cidade-monumento:

\section{Homens ricos do Brasil}

Que dais quinhentos contos por um puro sangue de corridas,

Está certo,

Mas dai também dinheiro para Ouro Preto.

\section{Grã-finas cariocas e paulistas}

Que pagais dez contos por um modelo de Christian Dior

E meio conto por um permanente no Baldini,

Está tudo muito certo,

mas mandai também dez contos para consolidar umas quatro casinhas de Ouro

[Preto (BANDEIRA, 1993, p. 220).

De certa forma, este poema traz de volta, com uma pitada irônica, os amigos não oficiais de Ouro Preto, a elite paulista que participou da viagem de redescoberta do Brasil em 1924: Paulo Prado, D. Olívia Guedes Penteado, Godofredo da Silva Telles, que sonharam, como vimos, em se associar para beneficiar as Igrejas de Minas. Bandeira parece sugerir, diante da mudança na ação da DPHAN, uma "Sociedade dos amigos dos casebres de taipa a sopapo", isto é, entaipados com o barro lançado à mão:

Bem sei que os monumentos veneráveis

Não correm perigo.

Mas Ouro Preto não é só o Palácio dos Governadores

A Casa dos Contos, 


\begin{abstract}
A Casa da Câmara,
Os templos,

Os chafarizes,

Os nobres sobrados da Rua Direita.
\end{abstract}

Ouro Preto são também os casebres de taipa de sopapo

Agüentando-se uns aos outros ladeira abaixo

O casario do Vira-Saia,

Que está vira-não-vira enxurro,

e é a isso que precisamos acudir urgentemente! (BANDEIRA, 1993, p. 219)

O poeta não apenas sugere a insuficiência financeira da DPHAN para a preservação do patrimônio, como critica, no órgão, na esteira de Mário de Andrade, um conceito monumentalista de patrimônio e, lembrando a sua própria crônica sobre Guignard, acima referida, na esteira de Drummond, aponta para um problema recorrente e atual em Ouro Preto: a ameaça constante das chuvas de verão sobre o casario barroco.

Os poemas acima vistos de Oswald e Bandeira tematizam a necessidade de preservação do conjunto arquitetônico colonial. Oswald, em 1924-1925, através de suas entrevistas, preconiza a ação da SPHAN; e Bandeira, admitindo, como os técnicos da DPHAN, que Ouro Preto muda, "que as coisas sempre cambiam" 7, diria Drummond, assinala os pontos problemáticos da cidade viva que ainda hoje ameaçam derruir a arquitetura barroca: o tráfego pesado, as chuvas de verão e o limite das verbas oficiais.

A cooperação entre o Estado e a Cultura é benéfica e responsável, no caso em questão, pela preservação do patrimônio arquitetônico barroco mineiro. Embora alguns critérios modernistas de preservação do patrimônio tenham se mostrado muitas vezes impraticáveis, a profissionalização do intelectual modernista como funcionário público mostrou-se positiva na construção da SPHAN.

Felizmente foi plantada a semente da preservação: desde a década de noventa do século XX, grandes cidades como o Rio de Janeiro investiram na restauração e no uso conveniente do patrimônio arquitetônico colonial e do Brasil Império, estreitando os laços entre a Cultura e o Estado, ao retomarem alguns conceitos e práticas de Mário de Andrade, cuja visão

7. Este verso é do poema "Morte das casas de Ouro Preto", de Drummond (ANDRADE, 1984, p, 81). Em outro poema sobre a cidade, surge um ponto de vista diverso. Em "Ouro Preto, Livre do Tempo", lê-se: "Ouro Preto, mais que lugar / sujeito à lei de finitude, / torna-se alado pensamento / que de pedra e talha se eleva / à gozosa esfera dos anjos". 
etnográfica e antropológica do patrimônio histórico e artístico nacional foi adotada pela DPHAN a partir dos anos 1960.

Pelo lado da poesia propriamente dita, os poemas acima vistos, ao denunciarem o estado precário do conjunto arquitetônico setecentista, designando inequivocamente a realidade, adquirem, para além da sua ficcionalidade, e sem prejuízo de outras interpretações ${ }^{8}$, um estatuto documental; em outras palavras, esta poesia de protesto, ao produzir a presença do mundo histórico implicado pela arquitetura barroca, também teve a sua hora e vez na preservação do patrimônio de Ouro Preto, atuando de forma realizadora e cívica.

\section{REFERÊNCIAS BIBLIOGRÁFICAS}

AMARAL, Aracy. Blaise Cendrars no Brasil e os Modernistas. Edição revista e ampliada. São Paulo: Fapesp/ Editora 34, 1997.

ANDRADE, Carlos Drummond de. Selo de Minas. In: . Claro Enigma. Nova Reunião. Vol. 1. Rio de Janeiro: José Olympio, 1983. . Corpo, novos poemas. za ed. Rio de Janeiro: Record, 1984.

ANDRADE, Mário de. O Aleijadinho e A Capela de Santo Antônio. In: Aspectos das artes plásticas no Brasil. za ed. Belo Horizonte: Itatiaia, 1984. . Mário de Andrade: cartas de trabalho: correspondência com Rodrigo Mello Franco de Andrade, 1936-1945. Brasília: SPHAN / Fundação Pró-memória, 1981.

ANDRADE, Oswald de. Os dentes do dragão: entrevistas. Pesquisa, organização e notas de Maria Eugênia Boaventura, za ed. São Paulo: Globo / Secretaria de Estado da Cultura, 1990. . Poesias Reunidas. Rio de Janeiro: Civilização Brasileira, 1978.

BANDEIRA, Manuel. Ouro Preto remoçada. In: . Andorinha, Andorinha. 2a ed. Rio de Janeiro: José Olympio, 1986.

. Estrela da Vida Inteira. 2oa Ed. Rio de Janeiro: Nova Fronteira, 1993.

. Guia de Ouro Preto. 4a ed. Rio de Janeiro: Ed. Ouro, [s. d.].

. Seleta de Prosa. Organização de Júlio Castañon Guimarães. Rio de Janeiro: Nova Fronteira, 1997.

CANDIDO, Antonio. Patrimônio interior. Revista do PHAN. Rio de Janeiro, n.22, p. 40-1, 1987 .

CARDOSO FILHO, Jusberto. Antologia Poética de Ouro Preto. Ouro Preto: Ed. Autor, 1995 .

8. Para uma bela interpretação do soneto “Ouro Preto”, de Manuel Bandeira, à luz do pensamento de Didi-Huberman, ver SCRAMIM, 2009. 
FURTADO, Celso. Pronunciamento do Ministro. Revista do PHAN. Rio de Janeiro. n. 22, p. $35,1987$.

HOUAISS, Antônio. Carlos Drummond de Andrade. In: Poetas do Modernismo. Vol. 3. Brasília: MEC/INL, 1972.

LIMA, Luis Costa. Oswald de Andrade. In: AZEVEDO FILHO, L. A., org. Poetas do Modernismo. Brasília: MEC/INL, 1972, p. 21- 43. Vol. 1

. O Estado e a Cultura. Revista do PHAN, Rio de Janeiro, n. 22, p. 18-21, 1987.

MATTA, Lia. A SPHAN em Ouro Preto: uma história de conceitos e critérios. Revista do PHAN. Rio de Janeiro, n. 22, p. 108-122, 1987.

MICELI, Sérgio. SPHAN: refrigério da cultura oficial. Revista do PHAN. Rio de Janeiro, n. 22, p. 44-47, 1987.

MORAES, Marcos Antonio de (org.). Correspondência: Mário de Andrade E Manuel Bandeira. São Paulo: Edusp, 2000.

SANTIAGO, Silviano. A permanência do discurso da tradição no modernismo e O intelectual modernista revisitado. In: Nas malhas da letra. São Paulo: Companhia das Letras, 1989. p. 94-123 e p. 165-175.

SCRAMIM, Susana. Poesia modernista. Gestos de ar e de pedra. Crítica cultural, Universidade do Sul de Santa Catarina, Santa Catarina, vol. 4, no 2, p. 227-234, 2009.

SILVA, Maximiano de Carvalho e. Manuel Bandeira: Defensor e Divulgador do Patrimônio Histórico e Artístico Nacional. In: (org.). Homenagem a Manuel Bandeira, 1986 -1988. Niterói: Sociedade Sousa da Silveira, Rio de Janeiro: Monteiro Aranha / Presença, 1989. p. 473-483.

SOUZA, Eneida Maria de. Mário Retorna a Minas. In: Traço crítico: ensaios. Rio de Janeiro: UFRJ; Belo Horizonte: UFMG, 1993. p. 145-154. 